\title{
Comparison of the Mechanical Behavior of Railroad Ballast in a Box Test under Sinusoidal and Realistic Train Loadings Using Discrete Element Method
}

\author{
Yahia Alabbasi \\ ya1107037@qu.edu.qa \\ Department of Civil and Architectural Engineering/ Qatar Transportation and Traffic \\ Safety Center, Qatar University, Doha, Qatar \\ Mohammed Hussein \\ mhussein@qu.edu.qa \\ Department of Civil and Architectural Engineering, Qatar University, Doha, Qatar.
}

\begin{abstract}
A ballasted track is a popular type of railway track and its use is increasing all over the world. A ballasted track consists of different structural elements like rails, fasteners, sleepers, ballast layer, sub-ballast layer and subgrade. A ballast layer is considered as the main structural element of ballasted tracks; it has a significant contribution to track stability and alignment. After service, periodical maintenance of ballast layer is required to maintain its functionality. Ballast maintenance is a cost and time expensive operation. Better understanding of ballast mechanical behavior leads to better ballast design and efficient maintenance. Discrete Element Method has been used extensively in the literature to understand the mechanical behavior of railroad ballast in a box test. Nevertheless, in the literature most of the studies simulate train loading as pure continuous sinusoidal loading unlike the real train loading. This paper aims to investigate the influence of the simulated train loading on the mechanical behavior of railroad ballast after 1000 loading cycles. There are two simulated train-loading cases used in this study for comparison purposes; continuous sinusoidal loading and a more realistic train loading utilizing the Beam on Elastic Foundation theory. The results show a difference of ballast vertical settlement up to $14 \%$ between the two simulated train-loading cases.
\end{abstract}

Keywords: Discrete element method; DEM; Railroad ballast; Ballasted track; Box test

\section{INTRODUCTION}

The use of railway transportation systems is increasing over the world. In many countries, a railway transportation system has a significant role as a means of transportation. The ballasted tracks have been used since the early commencement of railways. The ballasted track consists of two main structures; super structure and sub structure. The super structure consists of rails, fasteners and sleepers. The sub structure consists of ballast, sub ballast and subgrade.

The ballast element is the main element of ballasted track as it plays a vital role in maintaining the track stability and alignment. After service, periodical maintenance is required, which is an expensive operation (Indraratna, Ionescu \& Christie, 1998). Therefore, the research interest and work in relation to ballast mechanical behavior has 
been increasing to achieve a better ballast design and cost effective maintenance.

From the literature, Discrete Element Method (DEM) developed by (Cundall, 1971) has been used intensively to understand the mechanical behavior of railroad ballast. DEM is a powerful tool used to understand both the macroscopic and microscopic behavior of railroad ballast. DEM was used commonly for calibration and validation purposes. For example, particle crushing test (Lim \& McDowell, 2005), uniaxial test (Chung, Lin, Chou \& Hsiau, 2016), triaxial test (Qian, Lee, Tutumluer, Hashash \& Ghaboussi, 2018), direct shear test (Gong et al., 2019) and box test (Lim \& McDowell, 2005).

In the literature, large number of studies about the understanding of the mechanical behavior of railroad ballast using DEM via box test, simulate the loading coming from train as a pure continuous sinusoidal loading (Hossain, Indraratna, Darve \& Thakur, 2007; Ngo, Indraratna \& Rujikiatkamjorn, 2016). However, train loading has different shape, where each train car has four axles spaced in different spacing along the train. Each axle applies a load on the ballast layer. The loading from the train is dependent on the number of cars in the train, length of the car, weight of the car and spacing between axles.

The aim of this study is to investigate the influence of the simulated train loading type used in DEM to understand the mechanical behavior of railroad ballast. In this study, EDEM software by DEM Solutions is used for DEM analysis.

\section{DEM SETUP}

\subsection{Material Setup}

The first step in setting up the simulation is defining the properties of materials. In EDEM there are two types of materials used in the simulation; bulk and equipment materials. In this simulation, railroad ballast material is the bulk material and the box and sleeper materials are the equipment materials.

In this study, unbreakable spherical ballast shape with a rolling friction resistance approach is used. The main advantage of this approach is the low computational time compared to polyhedrons and multi-sphere approaches. Table 1, summarized the ballast material properties used in DEM model.

Table 1: Material Properties used in DEM

\begin{tabular}{|c|c|c|}
\hline Input used Parameters & Value & References \\
\hline Passions ratio & 0.2 & $\begin{array}{l}\text { (Ahmed, Harkness, Le Pen, } \\
\text { Powrie \& Zervos, 2016) }\end{array}$ \\
\hline Solid Ballast density & $2600 \mathrm{~kg} / \mathrm{m}^{3}$ & (Lim \& McDowell, 2005) \\
\hline Youngs Modulus & $17.7 \mathrm{GPa}$ & $\begin{array}{l}\text { (Irazábal, Salazar \& Oñate, } \\
\text { 2017) }\end{array}$ \\
\hline Coefficient of Restitution & 0.4 & (Farmer, 1968) \\
\hline Coefficient of Static Friction & 0.6 & \\
\hline Coefficient of Rolling Friction & 0.25 & (Irazábal et al., 2017) \\
\hline Contact Model & Hertz-Mindlin & $\begin{array}{l}\text { Ngo Ngoc, Indraratna \& } \\
\text { Rujikiatkamjorn, 2017) }\end{array}$ \\
\hline
\end{tabular}

For the equipment material, there are two equipment materials used in this study. Steel material for the box and concrete material for the sleeper. The simulated box portion of the track used in this study and the geometrical setup in EDEM are shown in Figure 1. 


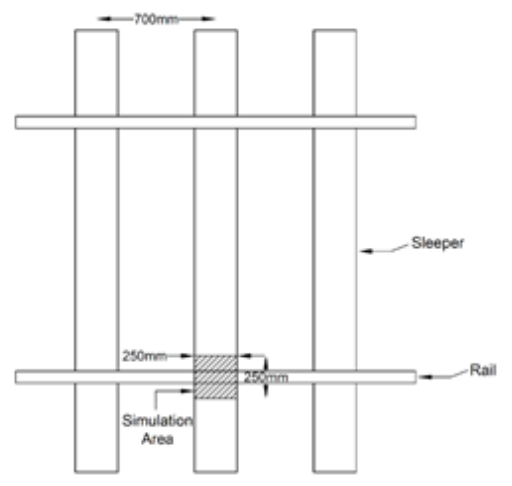

(a)

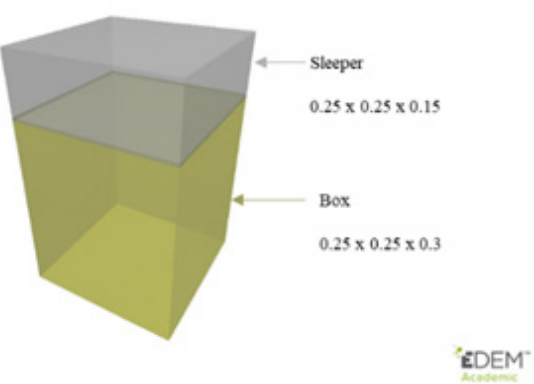

(b)

Figure 1: (a) Box simulation area of a railway track and (b) box geometrical set up used in EDEM (dimensions in meters).

\subsection{Control Mode}

EDEM software supports displacement control of the geometries. However, it can be customized to support force control mode by the Application Programming Interface (API) through $\mathrm{C}++$, which is the basic language of the software. In this study, force control mode is required to represent the different simulated train loading used in DEM. Therefore, number of $\mathrm{C}++$ codes were used to represent the different input simulated train loading used in EDEM (Alabbasi, 2019).

\subsection{Ballast Layer Creation and Preloading}

For particle creation, the physical box geometry is used in EDEM as dynamic factory (particles are created during the simulation). The input mass is $29.25 \mathrm{~kg}$ which is calculated based on a field bulk density of $1560 \mathrm{~kg} / \mathrm{m}^{3}$ and a box volume of $0.25 \times 0.25 \times 0.3$ meters. The boundaries of the steel box are considered as fixed in this simulation to represent the real large-scale box test (Lim \& McDowell, 2005).

The particles reached equilibrium, under their own weight, after 3 seconds of simulation time. At the start of the DEM simulation, the ballast material had a void ratio of 0.7 that corresponds to a bulk density of $1531 \mathrm{~kg} / \mathrm{m}^{3}$. Then, ballast layer is preloaded by $2.2 \mathrm{kN}$ that represents the static load from rail and sleeper weights on the simulation box. The calculation of preloading value is based on the common weights of rail and concrete sleepers. The preloading stage is applied and equilibrium state of ballast particles is achieved for 2 seconds of simulation time.

\section{LOADING CASES}

The train loading for this study is simulated for an infinite train passing the measurement point on the railway track. In this work, two loading scenarios are simulated and used in DEM.

Loading Case 1 represents the more realistic train loading which is simulated utilizing the Beam on Elastic Foundation (BOEF) theory, where rails were modelled as an EulerBernoulli beam discretely supported by rail pads to account for sleeper spacing. The rail 
pad was modelled as a spring with stiffness constant $\mathrm{k}_{\text {pad }}$. The measurement point is the location of the DEM simulation box test as shown in Figure 2. This part is considered as part 1 (Figure 2). In part 2, loading Case 1 is used as an input parameter.

Loading Case 2 represents, the most commonly training load type used in the DEM of railroad ballast in the literature. It is sinusoidal loading type. The usual loading frequency for normal trains is in the range of $8-10 \mathrm{~Hz}$ and for high speed trains it may extent to $30 \mathrm{~Hz}$; assuming an axle spacing of $2.6 \mathrm{~m}$ and a train speed of $75-94 \mathrm{~km} / \mathrm{hr}$ (Bhanitiz Aursudkij, 2007; B Aursudkij, McDowell \& Collop, 2009). For loading Case 2 the frequency used in this study equals to $11.11 \mathrm{~Hz}$ assuming a typical axle spacing $\left(\mathrm{L}_{1}\right)$ of $2.5 \mathrm{~m}$; and a train velocity of $100 \mathrm{~km} / \mathrm{hr}$ (Doha Metro maximum train speed).

The simulated train loading for Case 1 and Case 2 are shown in Figure 3. Point $\mathrm{A}$ and point $\mathrm{B}$ from Case 1 are used as a rang for the sinusoidal loading case for fair comparison purpose; where " $\mathrm{A}$ " is the maximum loading point and " $\mathrm{B}$ " is the minimum loading point. Point $\mathrm{C}$, represents the flying sleeper phenomena due to the more realistic simulated train loading utilizing BOEF theory. Points A, B and C equal to $-5.40 \times 10^{4} \mathrm{~N}$, $-2.21 \times 10 \times{ }^{3} \mathrm{~N}$ and $-696.82 \mathrm{~N}$ respectively.

In the field, ballast deformation and degradation occurs after a large number of loading cycles, beyond 100,000 (Hossain et al., 2007). However, the maximum number of loading cycles used in DEM to understand the mechanical behavior of railroad ballast is 4000 for a 3D model by (Ngo et al., 2016). This is due to the huge requirement of the computational time. Therefore, the number of loading cycles used in this study is 1000 loading cycles.

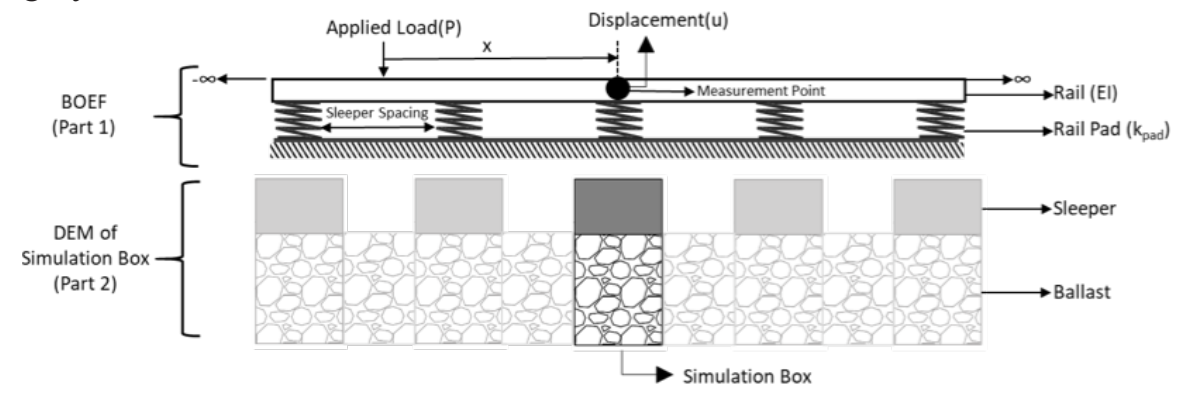

Figure 2: Infinite BOEF model used in this study to simulate train loading

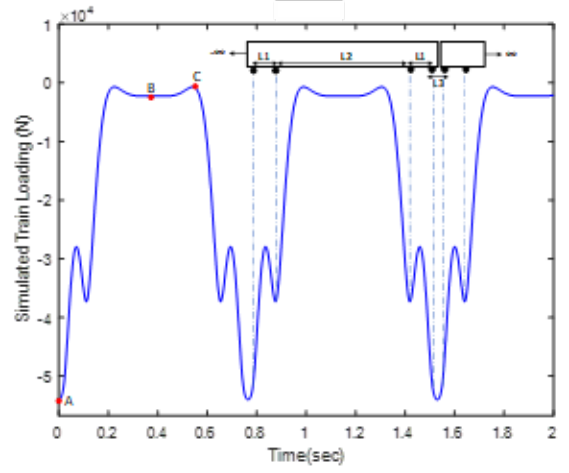

(a)

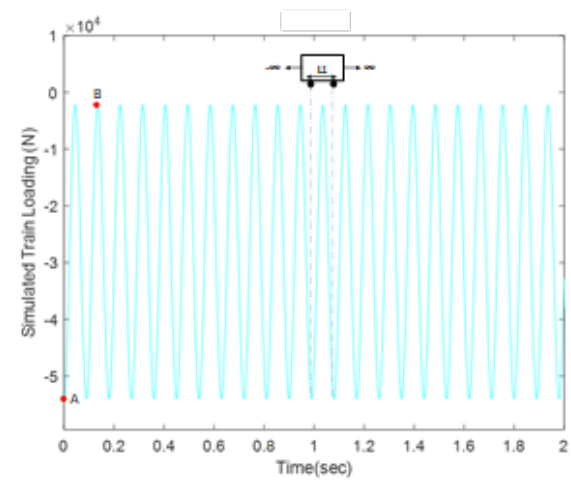

(b)

Figure 3: Loading Cases used in this study; (a) Case 1 and (b) Case 2 


\section{RESULTS AND DISCUSSION}

To investigate the influence of the simulated train loading used in DEM modelling on the macroscopic behavior of railroad ballast, the Absolute Maximum Displacement (AD) of ballast layer versus the number of loading cycles is used as shown in Figure 4. In this study, the displacement of ballast layer is taken as the displacement of sleeper.

A rapid displacement with high rate of change is observed at the initial 10 cycles as shown in Figure 5 (a). This is due to the rearrangement of ballast particles at the initial loading stage. Therefore, the requirement of ballast compaction is significant to reduce the initial settlement of ballast layer before service.

A gradual displacement with almost uniform rate of change is observed at the last 10 cycles as show in Figure 5 (b) because of ballast densification after number of loading cycles. This behavior agrees with the experimental investigations of (Ngo et al., 2016) where under loading cycles ballast layer endures three stages; Initial rapid displacement, gradual displacement and stabilization. In this study, the last stage (stabilization) is not observed because the number of applied loading cycles is low.

To compare the $\mathrm{AD}$ between the two loading cases, the difference at each single loading cycles is calculated as shown in Figure 6. It is observed that the type of simulated train loading used in DEM effects the mechanical behavior of railroad ballast. At the initial stage, the difference is maximum - almost $14 \%$ - due to the initial rapid displacement of ballast particles resultant of the dynamic effects related to sinusoidal loading as indicated in Figure 6. With the increase of loading cycles, the difference decreases to almost $5 \%$ at the last loading cycle due to the particle's rearrangement and densification.

One of the main advantages of DEM is the full insights to the microscopic behavior of discontinues material. In this study, the displacement of each ballast particle at the maximum loads of the 1000th cycle for the two loading cases (Figure 7) is used to observe and investigate the influence of simulated train loading on the microscopic behavior of railroad ballast. The vector represents the particle displacement and its direction.

It is observed for the both cases that at the maximum, load particles move downward and the opposite is at the minimum load of the $1000^{\text {th }}$ cycle. The movement of ballast particles at the maximum and minimum loads agrees with literature (Lim \& McDowell, 2005; Lobo-Guerrero \& Vallejo, 2006).

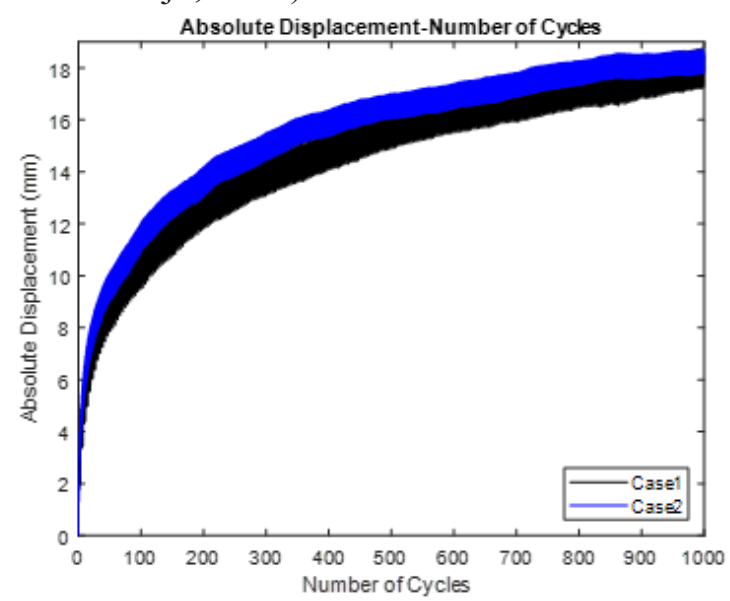

Figure 4: Absolute maximum displacement versus number of cycles for case 1 and case 2. 

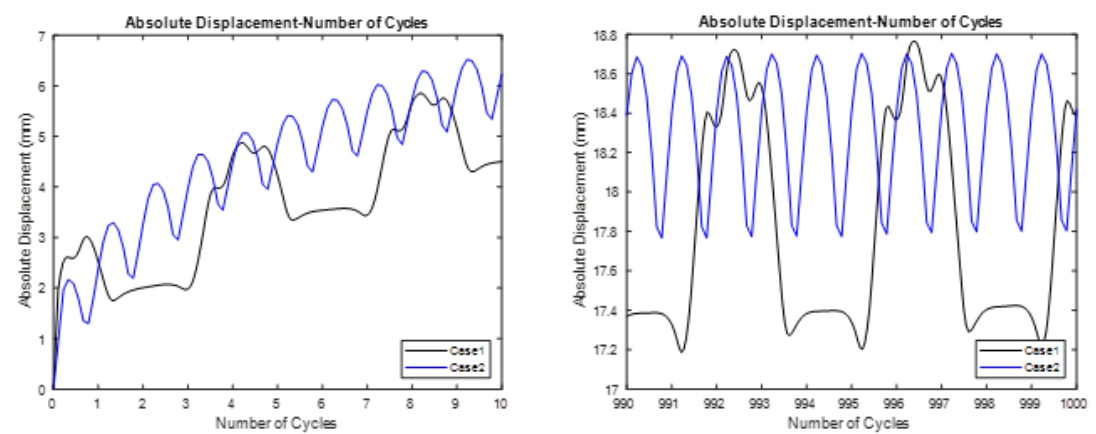

Figure 5: Absolute displacement of ballast layer for the both cases at the (a) initial stage (b) last stage

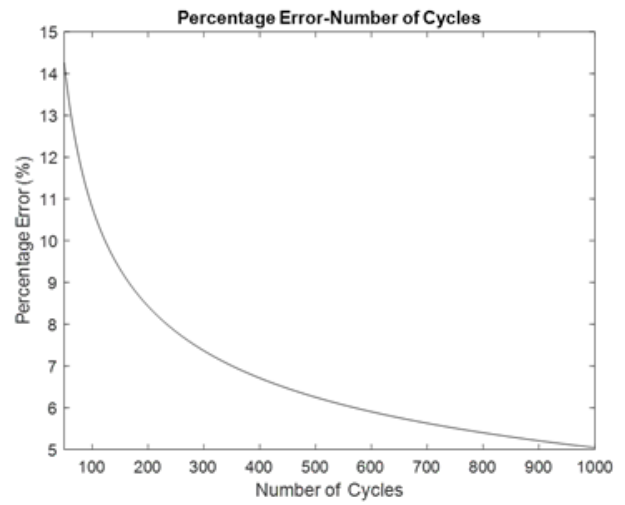

Figure 6: Difference percentage between the AD of ballast of both loading cases at each cycle

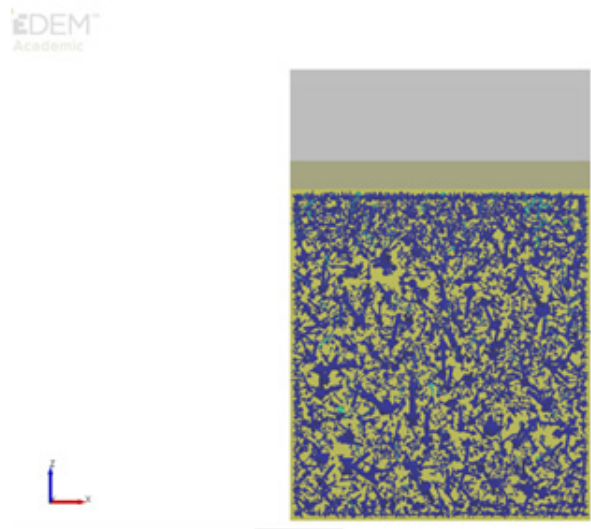

(a)

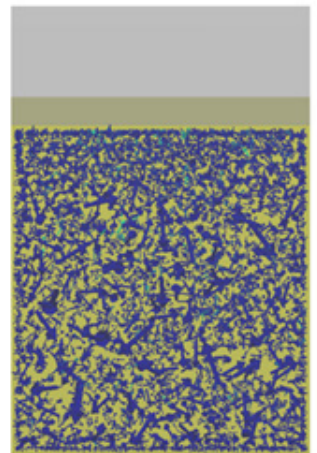

(b)

Figure 7: Particles displacements at maximum loads of the $1000^{\text {th }}$ cycle for (a) Case 1 and (b) Case 2 


\section{CONCLUSION}

The research interest and research work has been increasing throughout the years on understanding the mechanical behavior of railroad ballast for better design and efficient periodical maintenance.

DEM was used extensively in the literature to investigate the mechanical behavior of railroad ballast, most frequently through box test. The train loading was commonly simulated as pure continuous sinusoidal loading. However, trains consist of a number of cars and each car has a number of axles with different spacing in between the axles. Each axle applies a load on the track substructure. The train loading is not a pure continuous sinusoidal; it depends on the train weight, car length, axle number and axle spacing.

This study aims to investigate the influence of simulated train loading to understand the mechanical behavior of railroad ballast using DEM.

In the work presented in this paper, there are two simulated train-loading cases. Case 1 is the train loading simulated utilizing Beam on Elastic Foundation (BOEF) theory, which represents a more realistic train loading. The other case is sinusoidal loading (commonly used in literature).

In this study, the Beam on Elastic Foundation (BOEF) theory is utilized to analytically simulate a more realistic train loading. The numerical Discrete Element Method is used to simulate the behavior of railroad ballast via box test under the two loading cases. The results from the loading cases are compared:

The main findings of this study are briefly summarized as follows:

- DEM is a powerful method in understanding the mechanical behavior of discontinuous materiallikerailroad ballast.

- EDEM software is a useful tool to be used for DEM analysis.

- The type of the simulated train loading used in DEM of railroad ballast effects the mechanical behavior of railroad ballast where a maximum difference of ballast, absolute maximum displacement up to $14 \%$ is observed between the two loading cases.

Further investigation is required to account for large number of loading cycles; dynamic loading associated to high train speed, wheel and track irregularities; and particle breakage (permanent deformation).

\section{ACKNOWLEDGMENT}

This work has been carried out under a research project entitled "Framework for Research on Railway Engineering" which is supported by a grant sponsored by Qatar Rail with a grant reference number: QUEX-CENG-Rail 17/18.

\section{REFERENCES}

Ahmed, S., Harkness, J., Le Pen, L., Powrie, W. \& Zervos, A. (2016). Numerical modelling of railway ballast at the particle scale. International Journal for Numerical and Analytical Methods in Geomechanics, 40(5), 713-737.

Alabbasi, Y. (2019). Discrete Element Modeling of Railroad Ballast Under Simulated Train Loading. (Masters of Science in Civil Engineering Master). Qatar University, Doha, Qatar. Retrieved from http://hdl.handle.net/10576/11684. 
Aursudkij, B. (2007). A laboratory study of railway ballast behaviour under traffic loading and tamping maintenance.

Aursudkij, B., McDowell, G. \& Collop, A. (2009). Cyclic loading of railway ballast under triaxial conditions and in a railway test facility. Granular Matter, 11(6), 391.

Chung, Y. C., Lin, C. K., Chou, P. H. \& Hsiau, S. S. (2016). Mechanical behaviour of a granular solid and its contacting deformable structure under uni-axial compression - Part I: Joint DEMFEM modelling and experimental validation. Chemical Engineering Science, 144, 404-420. DOI: $10.1016 /$ j.ces.2015.11.024.

Cundall, P. A. (1971). A computer model for simulating progressive, large-scale movement in blocky rock system. Paper presented at the Proceedings of the International Symposium on Rock Mechanics.

Farmer, I. W. (1968). Engineering Properties of Rock-Spon. Google Scholar.

Gong, H., Song, W., Huang, B., Shu, X., Han, B., Wu, H. \& Zou, J. (2019). Direct shear properties of railway ballast mixed with tire derived aggregates: Experimental and numerical investigations. Construction and Building Materials, 200, 465-473. DOI: 10.1016/j. conbuildmat.2018.11.284.

Hossain, Z., Indraratna, B., Darve, F. \& Thakur, P. K. (2007). DEM analysis of angular ballast breakage under cyclic loading. Geomechanics and Geoengineering: An International Journal, 2(3), 175-181.

Indraratna, B., Ionescu, D. \& Christie, H. D. (1998). Shear behavior of railway ballast based on large-scale triaxial tests. Journal of Geotechnical and Geoenvironmental Engineering, 124(5), 439-449.

Irazábal, J., Salazar, F. \& Oñate, E. (2017). Numerical modelling of granular materials with spherical discrete particles and the bounded rolling friction model. Application to railway ballast. Computers and Geotechnics, 85, 220-229. DOI: 10.1016/j.compgeo.2016.12.034.

Lim, W. L. \& McDowell, G. R. (2005). Discrete element modelling of railway ballast. Granular Matter, 7(1), 19-29. DOI: 10.1007/s10035-004-0189-3.

Lobo-Guerrero, S. \& Vallejo, L. E. (2006). Discrete element method analysis of railtrack ballast degradation during cyclic loading. Granular Matter, 8(3-4), 195-204. DOI: 10.1007/s10035006-0006-2.

Ngo Ngoc, T., Indraratna, B. \& Rujikiatkamjorn, C. (2017). Micromechanics-Based Investigation of Fouled Ballast Using Large-Scale Triaxial Tests and Discrete Element Modeling. Journal of Geotechnical and Geoenvironmental Engineering, 143(2), 04016089. DOI: 10.1061/ (ASCE)GT.1943-5606.0001587.

Ngo, N. T., Indraratna, B. \& Rujikiatkamjorn, C. (2016). Modelling geogrid-reinforced railway ballast using the discrete element method. Transportation Geotechnics, 8, 86-102. DOI:10.1016/j.trgeo.2016.04.005.

Qian, Y., Lee, S. J., Tutumluer, E., Hashash, Y. M. A. \& Ghaboussi, J. (2018). Role of initial particle arrangement in ballast mechanical behavior. International Journal of Geomechanics, 18(3). DOI: 10.1061/(ASCE)GM.1943-5622.0001074. 